\title{
Azine Derivatives as a New Generation of Insect Growth Regulators
}

\author{
Martin Eberle ${ }^{\mathrm{a}}$, Saleem Farooq ${ }^{\mathrm{a}}$, André Jeanguenat ${ }^{\mathrm{a} *}$, Deborah Mousset ${ }^{\mathrm{a}}$, Arthur Steiger $^{\mathrm{a}}$, Stephan \\ Trah $^{a}$, Werner Zambacha, and Alfred Rindlisbacherb
}

\begin{abstract}
A new generation of insect-growth-regulator insecticides, the azines, are presented. They inhibit the chitin biosynthesis process and are active against lepidopteran pests. Their synthesis and a structure-activity relationship will be discussed.
\end{abstract}

Keywords: Chitin biosynthesis $\cdot$ Insecticide $\cdot 1,2,4$-Triazines

\section{Introduction}

The mode of action of many modern synthetic insecticides is linked to ubiquitous targets such as the nervous system or the respiration chain [1]. Although excellent selectivities for the target insects have been achieved with many insecticides, undesirable effects on non-target organisms (toxicity) and on the environment remain a recurrent problem. Specific insect targets, which are not found in other organisms have been previously recognized to play a prominent role for the discovery of safe new insecticides. Insect growth regulators (IGR) such as molting hormones (ecdysones, juvenile hormones, [2]) and chitin metabolism regulators are particularly attractive in this respect (see [1a], chap. 20).
Chitin is a highly organized polymer of $\mathrm{N}$-acetylglucosamine and is a major constituent of the cell wall of most fungal species as well as insects. It is rarely found in vertebrates and plants, where the analogous structural polymers are collagen and cellulose, respectively. During the insect molting process, a cocktail of chitin-related enzymes work towards the degradation of the old cuticle and the synthesis of the new one [3]. Inhibition of these processes has been a very successful approach towards the development of new classes of insecticides or fungicides [4]. The biosynthesis of chitin was targeted as early as 1972 at the Phillips-Duphar company, where the insecticidal benzoylphenylurea family (BPU, e.g. teflubenzuron (1a) and lufenuron (1b) Fig.) [5] was discovered. The BPUs disrupt the formation of chitin; the exact site of action has still not been elucidated. These compounds have a relatively limited insecticidal spectrum (lepidoptera) and are slow acting, as the insects will die only after the next regular molt. Closely related are the tetrazole acaricide clofentezine (2) [6a] and the experimental triazole insecticides (e.g. 3) [6b]. Ethoxazole 4 is a new generation acaricidal IGR with an oxazoline ring [6c]. Broad-spectrum insecticide-accaricides with an oxazoline moiety (e.g. 5a) were recently discovered [6d]. Their synthesis was possible by taking advantage of modern Pd-catalyzed aryl-aryl coupling reactions [7]. Pyrrolines 5b and imidazolines 5c represent the latest developments described in recent patent literature [6e][6f]. We discovered by serendipity that the acyl- urea group of the BPUs could be replaced by a number of 6 -membered ring heterocycles, leading to extremely potent lepidoptericides (e.g. 6). Comparing the X-ray structure of teflubenzuron (1a) [8] with oxazolines and our heterocyclic derivatives allows us to conclude that the new generation IGRs are possibly mimics of the best conformation of the BPUs (Fig.). We present here the synthesis of a range of heterocyclic derivatives.

\section{Chemistry}

\section{Synthesis of 1,2,4-Triazines A and B}

We were interested in the synthesis of 1,2,4-triazines of type $\mathbf{A}$ and $\mathbf{B}$ (Scheme 1). There are numerous ways to synthesize the 1,2,4-triazine core structure [9]. However selective methods for 3,5- or 3,6-disubstituted 1,2,4-triazines (A or $\mathbf{B}$ ) are rare. In a first approach, we decided to use a nonselective synthesis and separate both isomers by flash-chromatography. Coupling of the $\alpha$-keto-oxime 7 with the BOCamidrazone $\mathbf{8}$ delivered a 3:2 mixture of isomers 9 and 10. Both isomers were easily separated by flash-chromatography and elaborated to the final compounds via a Suzuki coupling (Scheme 1).

As the linear isomers of type $\mathbf{B}$ turned out to be much more potent than the isomers $\mathbf{A}$ in the insecticidal screening, a selective method for $\mathbf{B}$ was investigated. The cyclization of amidoximes $\mathbf{1 1}$ with $\alpha$-ketooximes 12 was already published (Scheme 2 , path a: [10] in collaboration with re- 


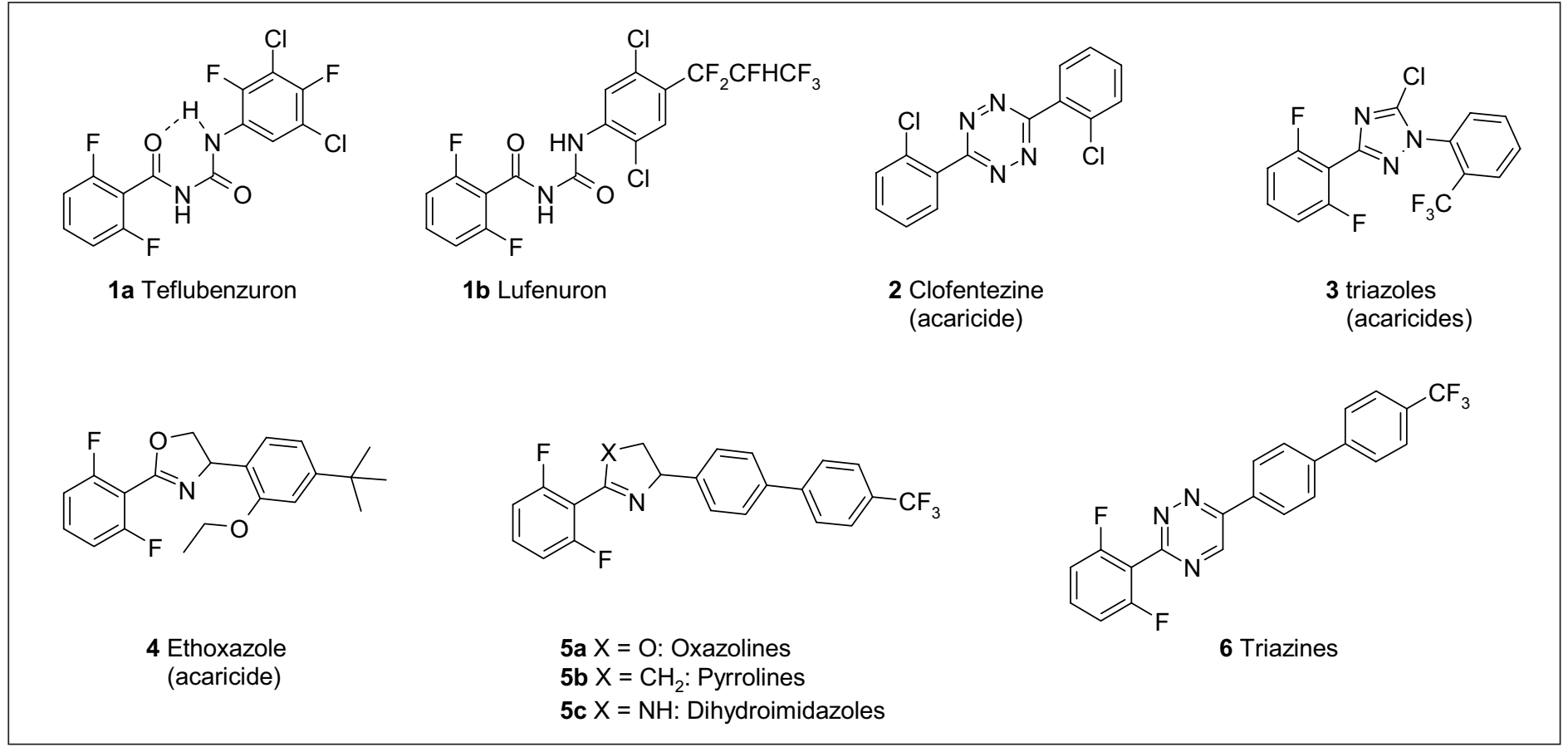

Fig. Insecticidal and acaricidal IGRs: from the BPUs to the triazines

searchers of Polyphor, Allschwil, CH). Under optimized conditions, linear triazines such as $\mathbf{1 3}$ were obtained in 75-85\% yield with only minor formation of triazines of type A. Another selective approach is the condensation of a thioimidate $\mathbf{1 4}$ with a hydrazino-oxime 15 [11]. We obtained the linear triazine exclusively in $40 \%$ yield. Suzuki coupling with arylboronic acids gave the final compounds B in high yields (85-97\%, Scheme 2, path b).

Compound $\mathbf{1 6}$ is a very versatile intermediate. While a bromine-metal exchange was not possible, $\mathrm{Pd}$-mediated reactions proved to be very valuable (Scheme 3, [7]). Suzuki arylation (route a and b/c), Heck coupling (route d), Sonogashira coupling (route e) and Buchwald-Hartwig amination (route f) delivered a set of compounds with a high diversity in physico-chemical properties. In each case the conditions had to be optimized (catalyst, ligands, solvent, base). The reported conditions are valid for a very diverse set of coupling partners.

\section{Synthesis of Pyridines C}

Pyridine analogues of $\mathbf{B}$ were easily prepared via cyclocondensation of triazines B with bicyclo[2.2.1]hepta-2,5-diene, followed by molecular nitrogen extrusion and a retro-Diels-Alder reaction [12]. Pyridines C were obtained in 30 to $75 \%$ yield (Scheme 4).

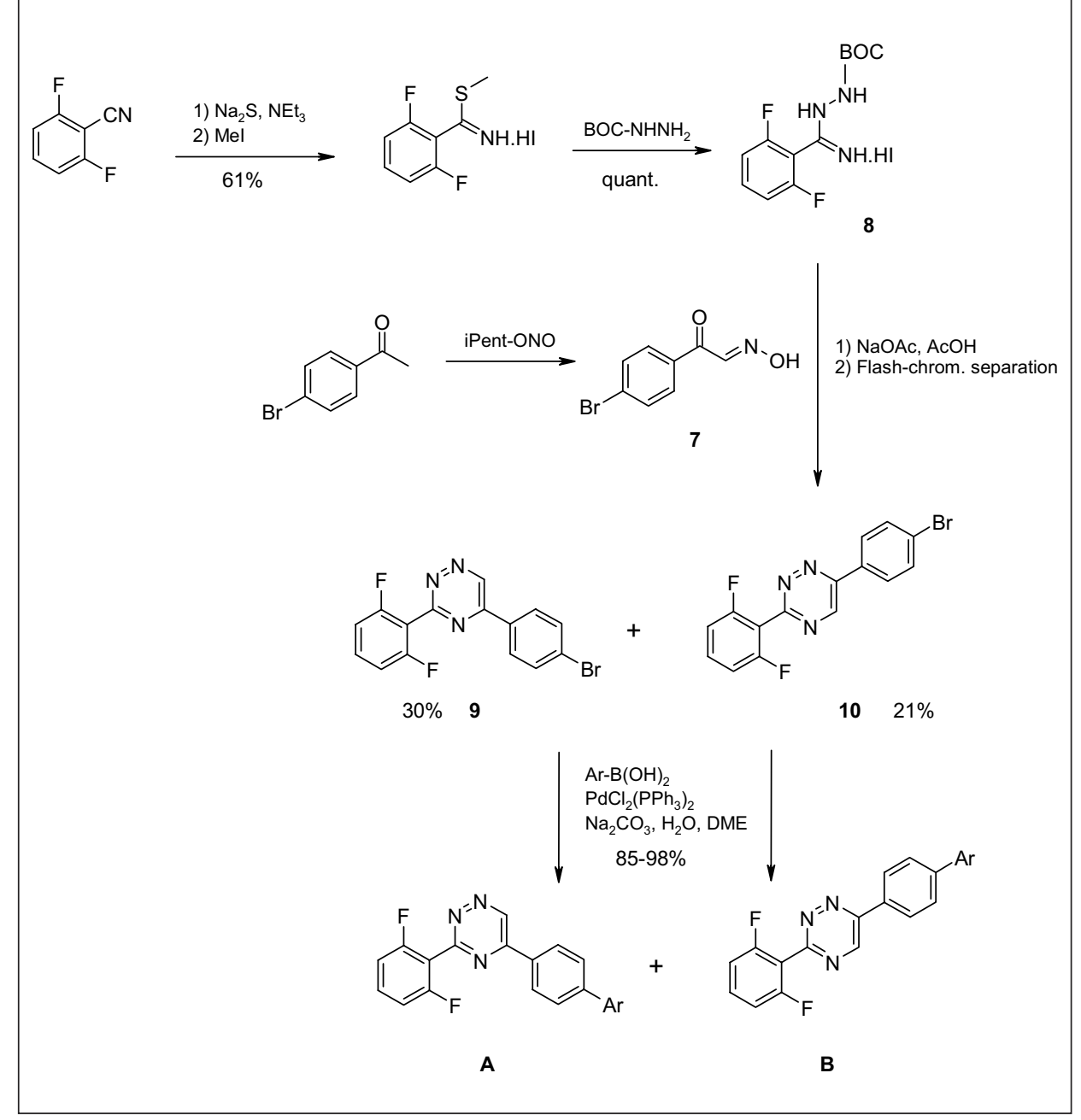

Scheme 1. Synthesis of 3,5- and 3,6-disubstituted 1,2,4-triazines A and B 


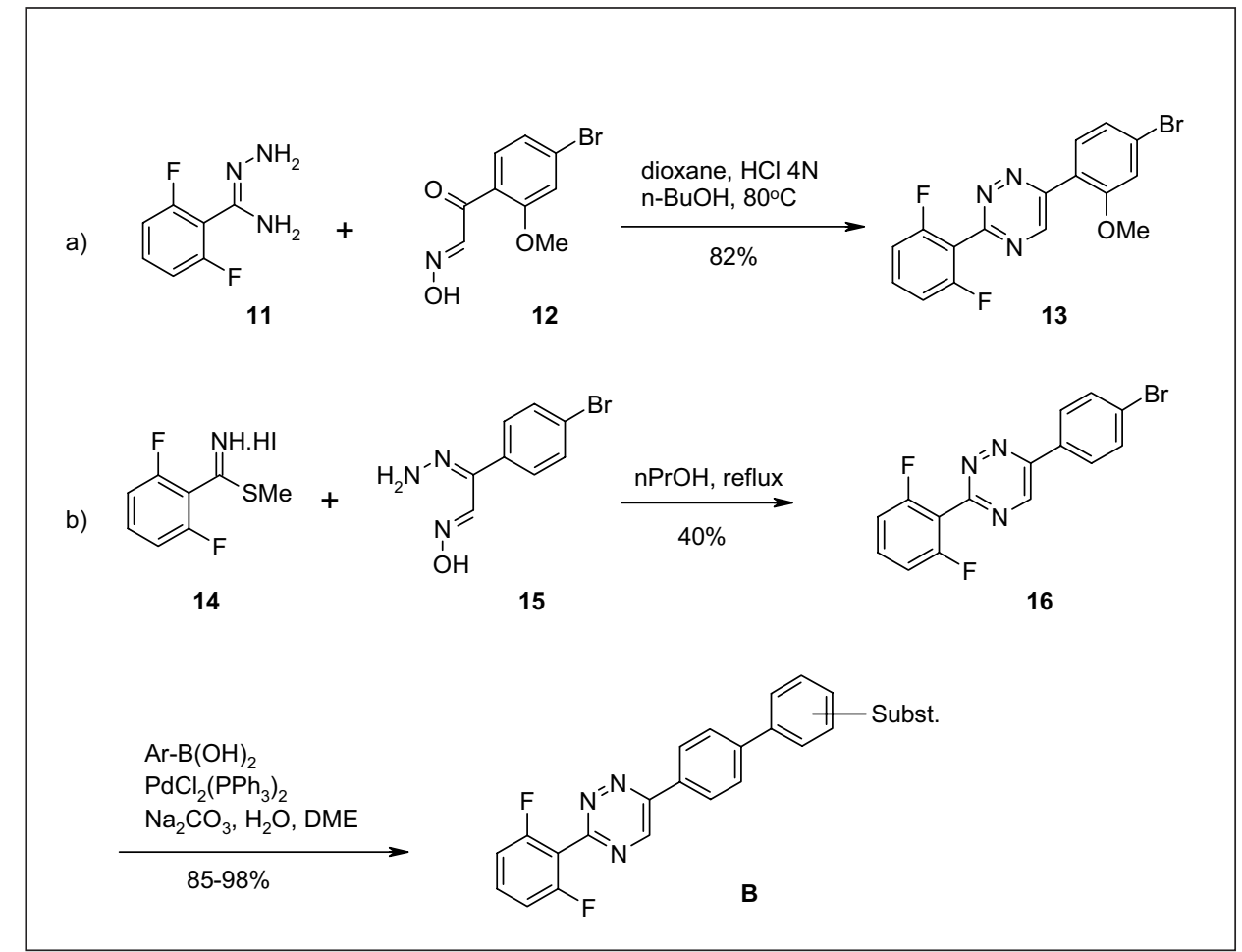

Scheme 2. Selective synthesis of 3, 6-disubstituted 1,2,4-triazines B

\section{Synthesis of Tetrazines $D$ and Pyridazines $E$}

Tetrazine analogues of $\mathbf{B}$ were prepared by chlorination of a diacyl-hydrazine $\mathbf{2 2}$ followed by cyclization with hydrazine. Aromatization of the obtained dihydrotetrazines $23\left(\mathrm{NaNO}_{2}, \mathrm{AcOH}\right)$ and Suzuki coupling yielded tetrazines $\mathbf{D}$ in good yields (Scheme 5). Pyridazine $\mathbf{2 5}$ was readily made by condensation of the tetrazine intermediate $\mathbf{2 4}$ with acetaldehyde enolate (two steps or concerted cycloaddition) followed by nitrogen extrusion and water elimination [13]. Suzuki coupling gave the final pyridazines $\mathbf{E}$ in high yield.

\section{Synthesis of Pyrimidines $F$ and Tetrahydropyrimidines $\mathbf{G}$}

Pyrimidine analogues of $\mathbf{B}$ were prepared by condensation of an amidine $\mathbf{2 6}$ with a vinamidinium salt 27 [14]. The conditions of the final Suzuki coupling were critical, as the chlorine substituents in the vicinity of the pyrimidine nucleus are activated for cross coupling (Scheme 6). Catalytic reduction of the pyrimidines $\mathbf{F}$ gave the tetrahydropyrimidines $\mathbf{G}$, which are close analogues of the imidazolines $\mathbf{5 c}$ (Fig.). Halogen substituents ( $\mathrm{Cl}$ or $\mathrm{Br}) \mathrm{did}$ not survive these conditions and were reduced.

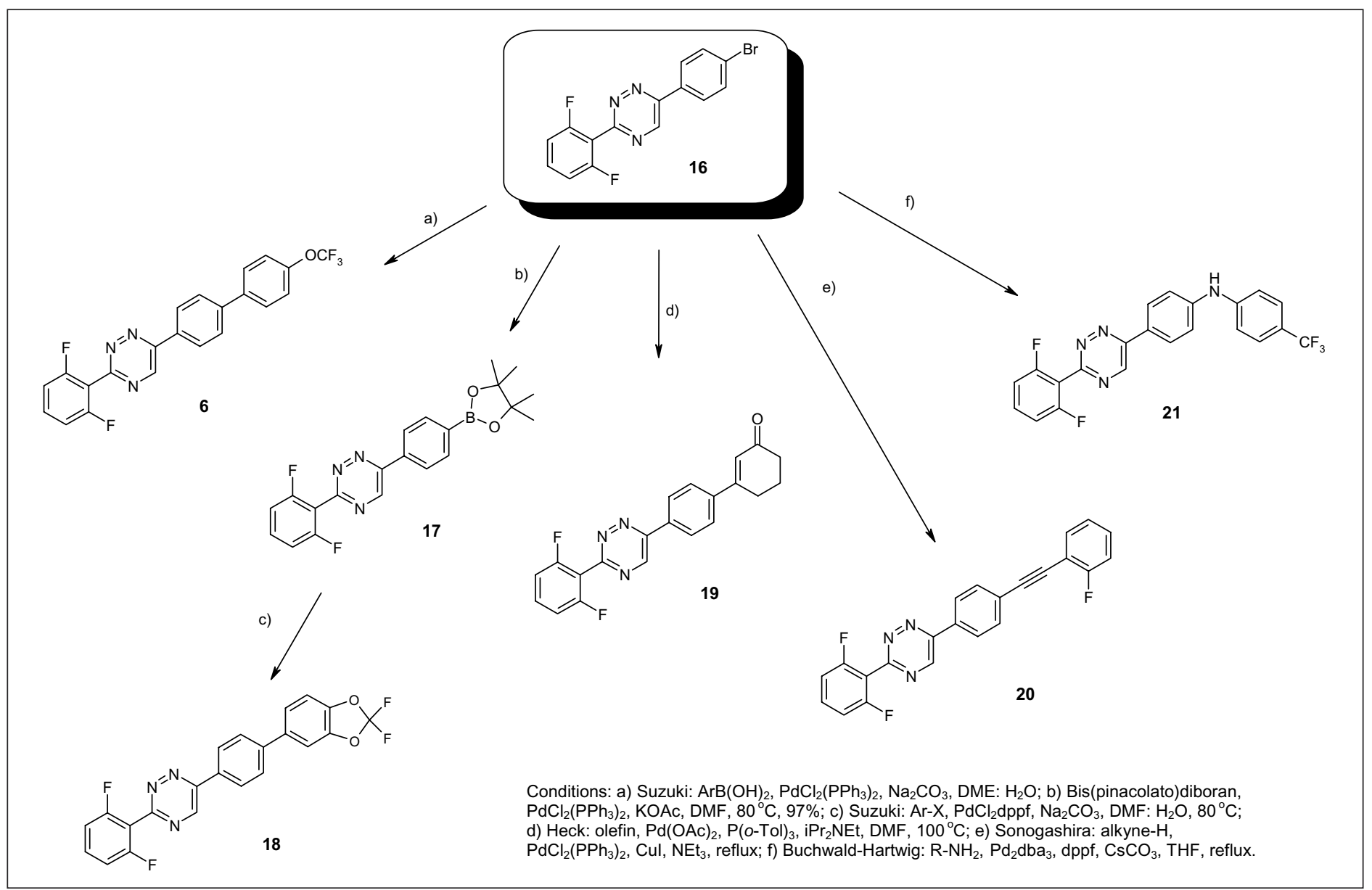

Scheme 3. Pd-mediated derivatisation of 16 


\section{Biological Activity}

These new azines turned out to be extremely potent in greenhouse assays against key lepidopteran pests. Activity against cotton leaf worm (Spodoptera littoralis), tobacco budworm (Heliothis virescens) and diamondback moth (Plutella xylostella) for typical compounds are listed in the Tables 1 and 2. Especially remarkable is the complete control of Spodoptera larvae at concentration as low as $0.05 \mathrm{ppm}$ ! Some interesting activity was also found against mites (Tetranychus urticae), white flies (Bemisia tabaci), thrips (Frankliniella occidentalis), and scales (Aonidiella aurantii), demonstrating the potential of this new class of insecticides.

\section{Variation of the Heterocycle}

For each variation except the pyridazines (Table 1, entries 7 and 8), the activity against Spodoptera was outstanding and comparable or even better than that of the most efficient commercial standards (data of the BPU lufenuron are shown for comparison). The triazines displayed a broad spectrum of activity (entries 1 and 2), which included sucking insects (data not shown).

\section{Variation of the Substituents on the Triazine Analogues}

The best substituents $\mathrm{X}^{1}, \mathrm{X}^{2}$, and $\mathrm{X}^{3}$ on the phenyl ring in the position 3 of the triazines are listed in Table 2 (entries 1 to 4 ). They are reminiscent of the best substituents of the BPUs or of the triazoles (see Fig., 1 and 3). Ortho substituents on the phenyl ring in the position 6 of the triazine are tolerated ( $R$, entries 5 and 6). This indicates that the rings are probably not coplanar but rather perpendicular as confirmed by a conformation analysis (data not shown). Substituents $S^{1}, S^{2}$, and $S^{3}$ on the last phenyl group (entries 7 to 10) dramatically influence the spectrum of activity. Substituents in position $4\left(\mathrm{~S}^{1} \neq \mathrm{H}\right)$ or $3\left(\mathrm{~S}^{2} \neq \mathrm{H}\right)$ are tolerated.

In conclusion we have found a new generation of IGRs with outstanding activity in the greenhouse against commercially important lepidopteran pests and interesting properties against some sucking pests. The activity of the triazines was confirmed in worldwide field trials in cotton and vegetables.

Received: September 15, 2003

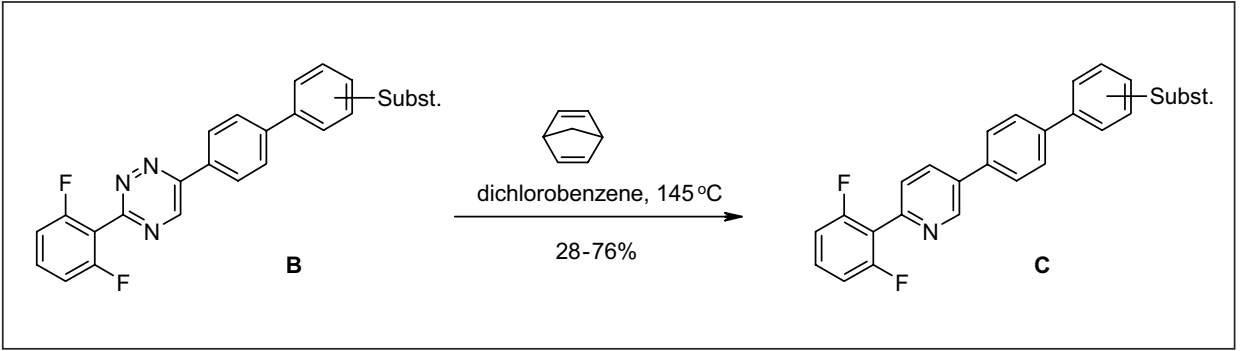

Scheme 4. Synthesis of pyridine analogues $\mathbf{C}$

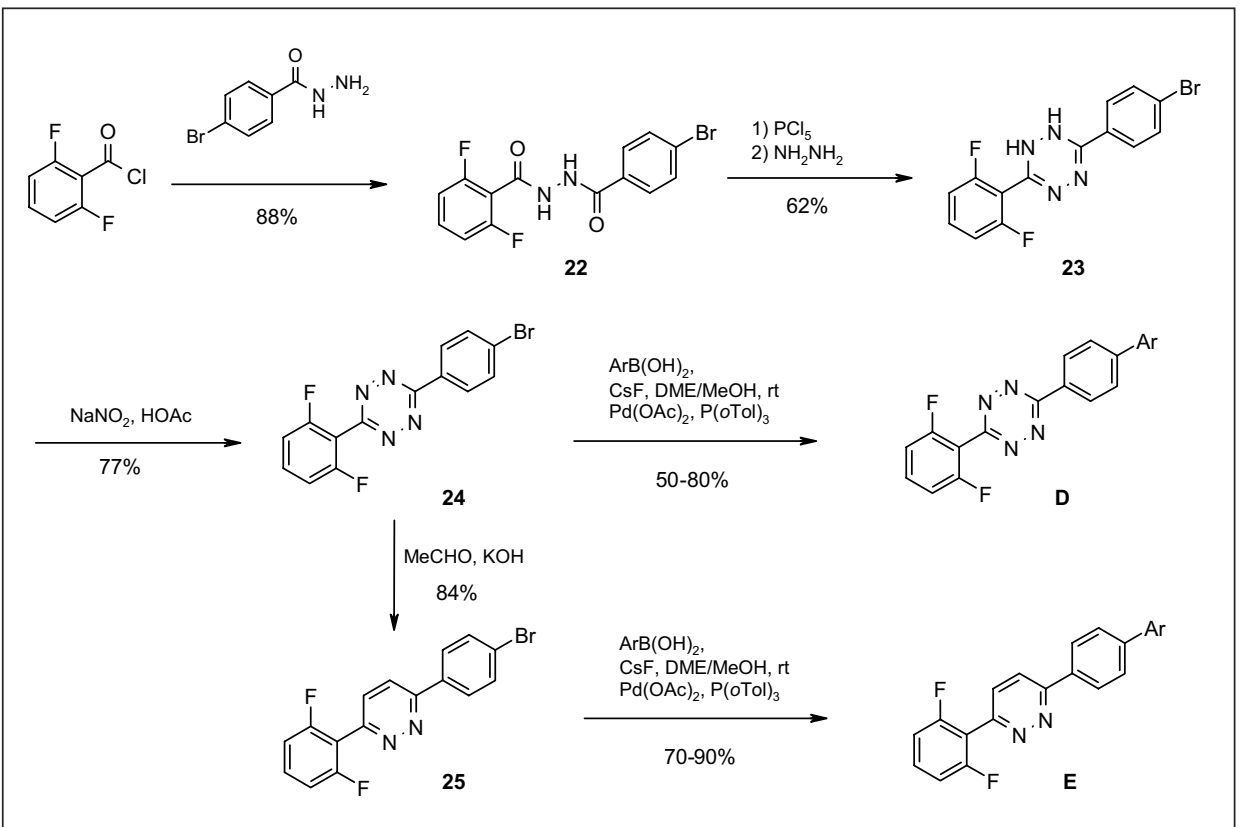

Scheme 5. Synthesis of tetrazine and pyridazine analogues $\mathbf{D}$ and $\mathbf{E}$

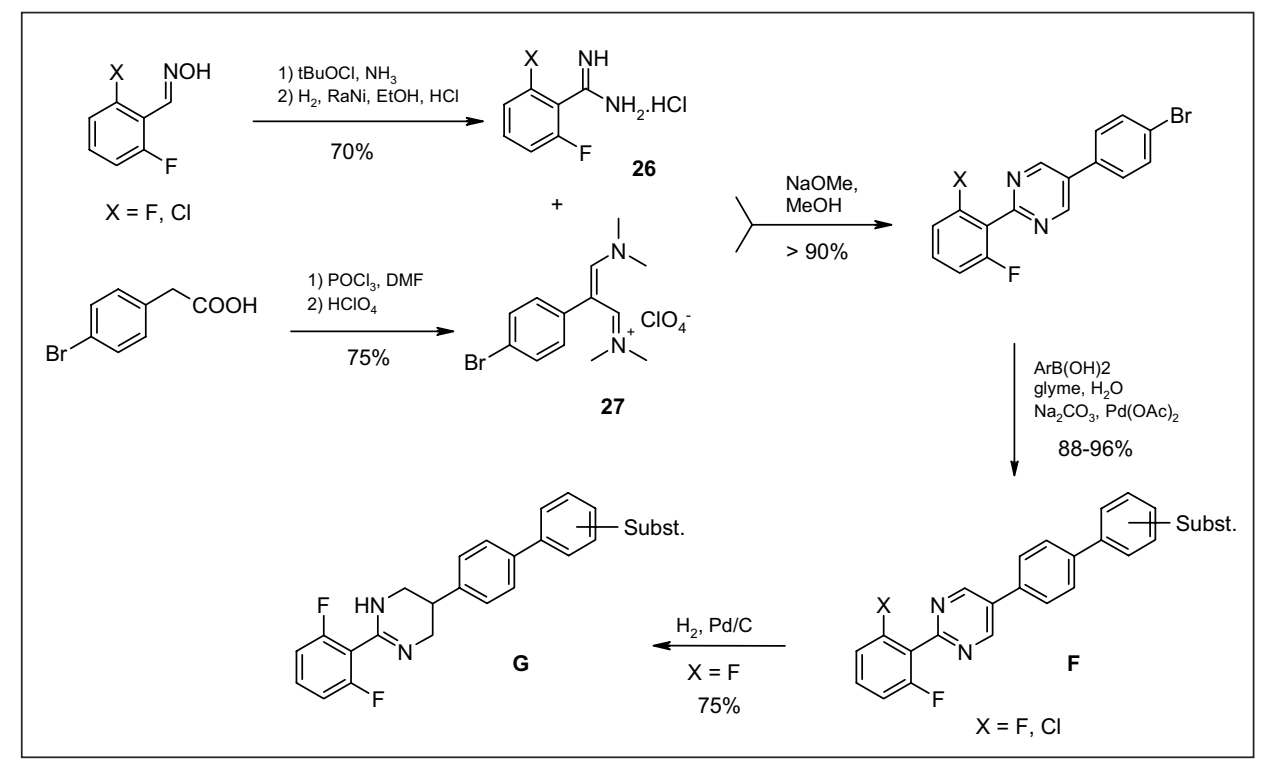

Scheme 6 . Synthesis of pyrimidine and tetrahydropyrimidine analogues $\mathbf{F}$ and $\mathbf{G}$ 
Table 1. Structure-activity relationship of the azines B-G

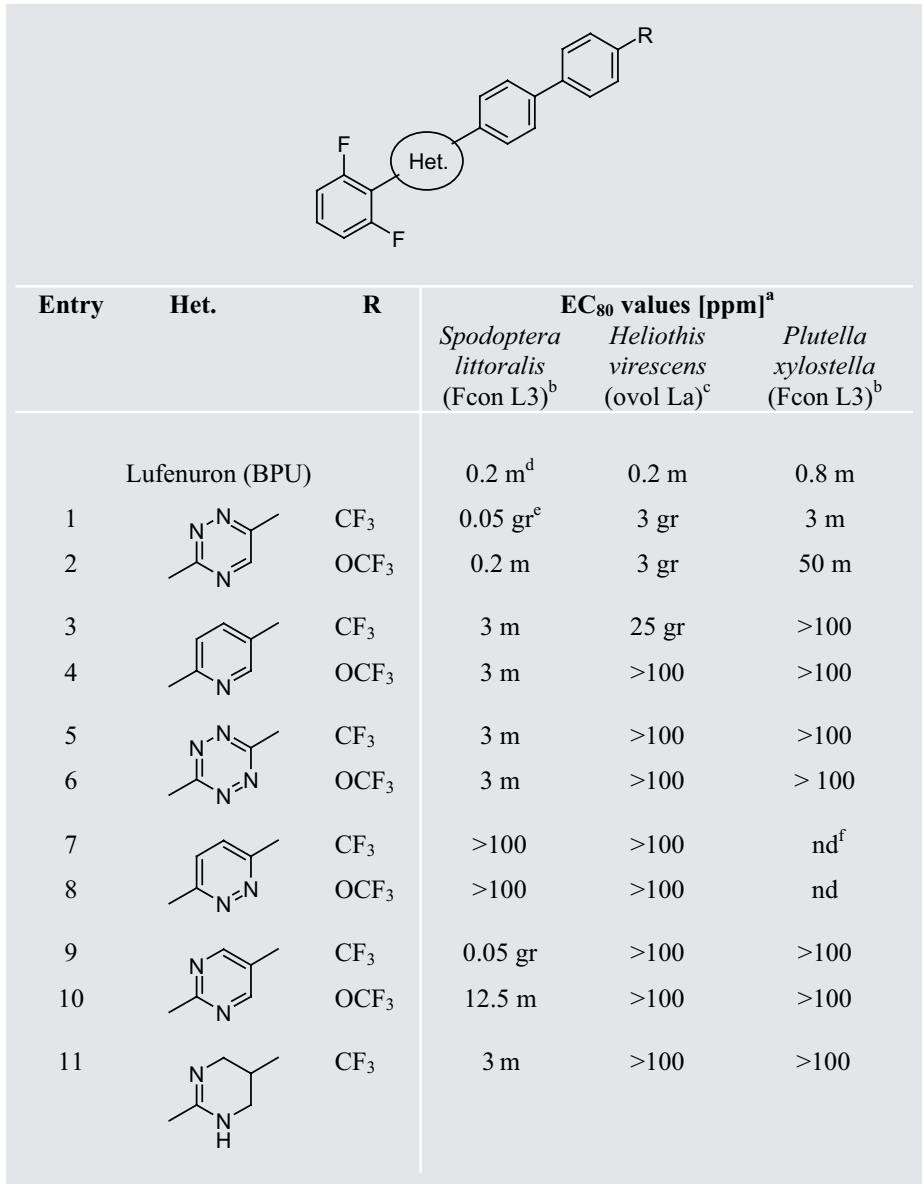

${ }^{a} \mathrm{EC}_{80}$ value: concentration in ppm for which the tested compound shows at least $80 \%$ ac-

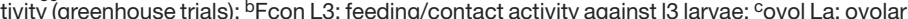
vicide test, effect on larvae; ${ }^{\mathrm{d}} \mathrm{M}$ : mortality effect; ${ }^{\mathrm{e}}$ gr: growth inhibition; ${ }^{\mathrm{f}}$ not determined.
Table 2. Structure-activity relationship of the triazine analogues B

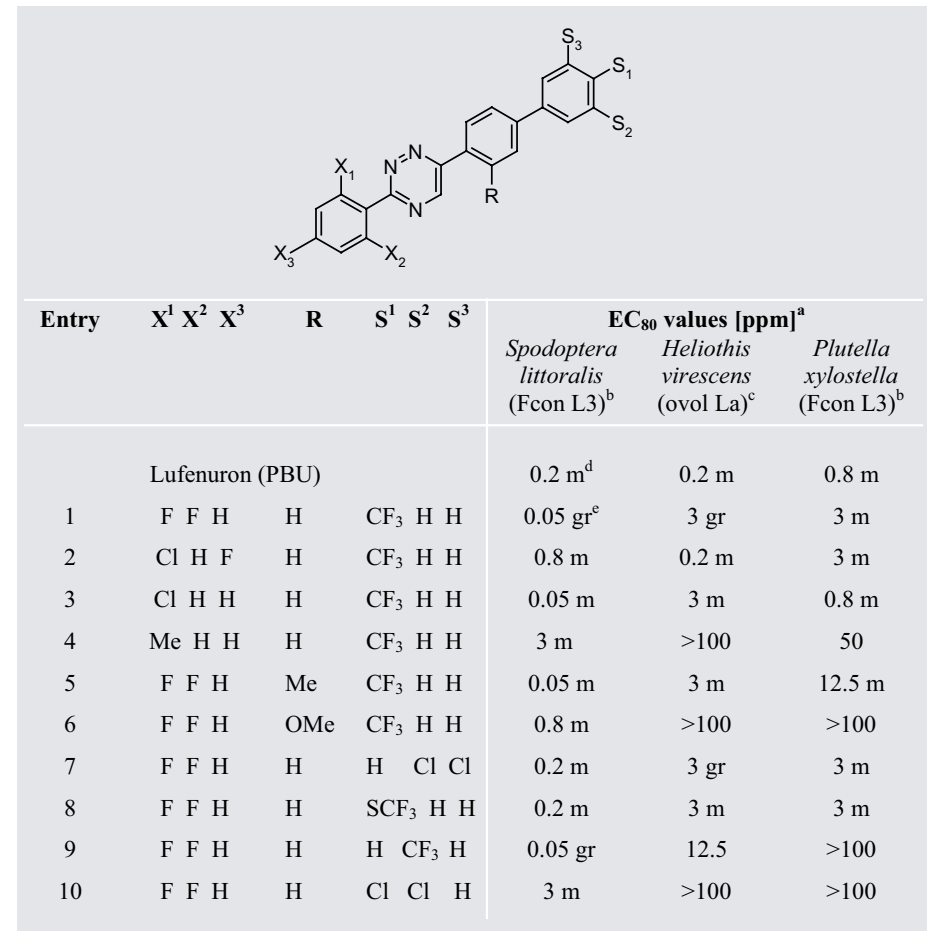

${ }^{a} \mathrm{EC}_{80}$ value: concentration in ppm for which the tested compound shows at least $80 \%$ activity (greenhouse trials); ${ }^{b} F c o n$ L3: feeding/contact activity against I3 larvae; ' ${ }^{\circ}$ vol La: ovolarvicide test, effect on larvae; ${ }^{\mathrm{d}} \mathrm{M}$ : mortality effect; " ${ }^{2}$ r: growth inhibition.
[1] a) A.S. Perry, I. Yamamoto, I. Ishaaya, R.Y. Perry, 'Insecticides in Agriculture and Environment', Springer, Berlin, 1998; b) 'Biochemical Sites of Insecticide Action and Resistance', Ed. I. Ishaaya, Springer, Berlin, 2001; c) 'Insecticides with Novel Modes of Action' Eds. I. Ishaaya, D. Degheele, Springer, Berlin, 1998; d) M. Eto in 'Chemistry of Plant Protection 6', Springer, Berlin, 1990, p. 65.

[2] G. Gäde, K.H. Hoffmann, J.H. Spring, Physiol. Rev. 1997, 77, 962.

[3] a) E. Cohen, Pest Manag. Sci. 2001, 57 946; b) E. Cohen, Arch. Insect Biochem. Physiol. 1993, 22, 245; c) G.W. Gooday in 'Biochemistry of Cell Walls and Membranes in Fungi', Eds. P.J. Kuhn, A.P.J. Trinci, M.J. Jung, N.W. Goosey, L.G. Cooping, Springer, Berlin, 1990; d) S.E. Reynolds, Pestic. Sci. 1987, 20, 131; e) D.M. Rast, M. Horsch, R. Furter, G. Gooday, J. Gen. Microbiol. 1991, 137, 2797.

[4] a) A.K. Tripathi, V. Prajapati, S.P.S Khanuja, S. Kumar, J. Med. Arom. Plant Sci. 2002, 24, 104; b) D.M. Rast, R.A. Merz, A. Jeanguenat, E. Mösinger, Advan. Chitin Sci. 2000, 4, 479; c) M. Horsch, C. Mayer, U. Sennhauser, D.M. Rast, Pharmacol. Ther. 1997, 76, 187.
[5] W. Maas, R. van Hes, A.C. Grosscurt, D.H. Deul, in 'Chemie der Pflanzenschutz- und Schädlingsbekämpfungsmitteln', Ed. R. Wegler, Springer, 1981, 6, p. 424.

[6] a) 'The Pesticide Manual', Ed. C.D.S Tomlin, British Crop Protection Council, Farnham, UK, 12th edition, 2000, p. 189. b) C. Luethy, R. Zurflueh (Hoffmann-La Roche), EP 208321, 1986; c) T. Ishida, J. Suzuki, Y. Tsukidate, Brighton Crop Prot. Conf.-Pests Dis. 1994, 2, 37; d) T.M. Stevenson, V.E. Amoo, G.C. Chiang, E. Keskeny, J.K. Long, B.A. Crouse, P. Sharpe, K. Hillegass, L. Jones, C. Yatsko in 'Synthesis and Chemistry of Agrochemicals VI', Eds. D.R. Baker, J.G. Fenyes, G.P. Lahm, T.P. Selby, T.M. Stevenson, ACS Symposium Series 800, ACS, Washington, 2002; e) A. Graff, A. Plant, C. Erdelen, N. Mencke, A. Turberg (Bayer AG), WO 2000/03995, 2000; f) A. Plant, G. Kleefeld, T. Potter, C. Erdelen, N. Mencke, A. Turberg, U. WachendorffNeumann, (Bayer AG), WO 1998/22438, 1998.

[7] a) 'Metal-catalyzed Cross-coupling Reactions', Eds. F. Diederich, P.J. Stang, Wiley-VCH, Weinheim, 1998; b) A.R. Muci, S.L. Buchwald, Topics Curr. Chem. 2002, 219, 131 .
[8] a) Z. Li, X. Qian, Z. Zhu, Z. Xia, J. Sun, Chem. Research 1998, 478; b) X. Qian, J. Agric. Food Chem. 1999, 47, 4415.

[9] H. Neunhoeffer in 'Comprehensive Heterocyclic Chemistry II', Eds. A.R. Katritzky, C.W. Rees, E.F.V. Scriven, Pergamon Press, Oxford, 1996, Vol. 6, p. 507.

[10] M. Altorfer, P. Ermert, J. Fässler, S. Farooq, E. Hillesheim, A. Jeanguenat, K. Klumpp, P. Maienfisch, J.A. Martin, J.H. Merret, K.E.B. Parkes, J.P. Obrecht, T. Pit terna, D. Obrecht, Chimia, 2003, 57, 262.

[11] For a related reaction giving 1,2,4-triazines 4-N-oxide, see: V. Böhnisch, G Burzer, H. Neunhoeffer, Liebigs Ann. Chem. 1977, 1713.

[12] G.R. Pabst, J. Sauer, Tetrahedron Lett 1998, 39, 6687. For an excellent review on that chemistry and its application in heterocyclic synthesis and natural product synthesis, see D.L. Boger, ChemTracts Org. Chem. 1996, 9, 149.

[13] M.J. Haddadin, S.J. Firsan, B.S. Nader, $J$ Org. Chem. 1979, 44, 629.

[14] H. Zaschke, Z. Chem. 1977, 17, 63. 